\title{
Cryoprecipitate transfusion: current perspectives
}

This article was published in the following Dove Press journal:

International Journal of Clinical Transfusion Medicine

22 September 2016

Number of times this article has been viewed

\section{Henna Wong \\ Nicola Curry \\ Oxford Haemophilia and Thrombosis Centre, Churchill Hospital, Oxford University Hospitals NHS Foundation Trust, Oxford, UK}

\begin{abstract}
Cryoprecipitate is prepared by controlled thawing of frozen plasma and is a rich source of fibrinogen, FVIII, von Willebrand factor, Factor XIII, and fibronectin. It is mainly transfused in Western countries as a concentrated source of fibrinogen replacement for acquired hypofibrinogenemia. During major bleeding, fibrinogen is the first clotting protein to be depleted to critically low levels. Increasing recognition of the importance of maintaining fibrinogen levels in bleeding has led to significant interest in appropriate fibrinogen supplementation. This review presents an overview of the indications, use and evidence for cryoprecipitate transfusion in hemorrhage, how it may promote hemostasis, and recent developments in extended thaw cryoprecipitate.

Keywords: cryoprecipitate, fibrinogen, hypofibrinogenemia, major hemorrhage, bleeding
\end{abstract}

\section{Introduction}

Cryoprecipitate was first discovered as a source of factor VIII and von Willebrand factor (VWF) and used to treat congenital hemophilias. ${ }^{1,2}$ In current practice, it is mainly used as a concentrated source of fibrinogen for treatment of acquired hypofibrinogenemia. For many years, it has been recognized that fibrinogen is one of the key coagulation proteins important for hemostasis. More recently, in the context of major hemorrhage, studies on trauma and obstetric bleeding have shown that acquired hypofibrinogenemia is an adverse parameter associated with inferior outcomes and coagulopathy. This has provoked much interest in optimal timing and dosing of fibrinogen replacement in active hemorrhage. However, is cryoprecipitate outmoded? In this review, we present an overview of cryoprecipitate therapy and focus on the recent developments in use of cryoprecipitate and discuss the alternative sources of fibrinogen supplementation in acquired hypofibrinogenemia.

\section{Cryoprecipitate: history and content}

In the $1960 \mathrm{~s}$, Pool et $\mathrm{al}^{1}$ discovered that when frozen plasma was allowed to thaw slowly, it precipitated and became a rich source of FVIII, VWF, XIII, and fibrinogen. ${ }^{3}$ The principal steps in the preparation of cryoprecipitate remain the same today; frozen plasma undergoes controlled thawing at $1^{\circ} \mathrm{C}-6^{\circ} \mathrm{C}$ to precipitate high molecular weight proteins. ${ }^{4,5}$ These proteins are then separated by centrifugation and resuspended in a small volume of plasma and stored at $-18^{\circ} \mathrm{C}$ or even lower temperatures. In the $\mathrm{UK}$, cryoprecipitate is available as a single-donor pack or as pools of $5 \mathrm{U}$ (five donor exposure). ${ }^{6}$
Correspondence: Henna Wong

Oxford Haemophilia and Thrombosis

Centre, Churchill Hospital, Old Road,

Oxford OX3 7LE, UK

Tel +44I865225300

Fax +44I865 225608

Email henna.wong@ouh.nhs.uk 


\section{Content of cryoprecipitate}

Cryoprecipitate is a plasma-derived blood product containing a rich source of fibrinogen and high concentrations of FVIII, VWF, and FXIII (Table 1). ${ }^{6-9}$ It also contains fibronectin, platelet microparticles, and a small amount of immunoglobulins. ${ }^{7}$ Due to differences in the manufacturing process and variability between blood donors, the concentration of fibrinogen varies in cryoprecipitate $(\sim 3-30 \mathrm{~g} / \mathrm{L}){ }^{3}$ Some blood transfusion services stipulate a minimum fibrinogen concentration per pack of cryoprecipitate, eg, from UK Blood Transfusion Service, $75 \%$ of packs should contain $\geq 140 \mathrm{mg}$ of fibrinogen. ${ }^{10}$ According to the UK guidelines, cryoprecipitate must be used within 4 hours of thawing, if stored at room temperature. ${ }^{6}$

\section{Why is fibrinogen important? Role of fibrinogen in clot formation}

Fibrinogen plays a critical role in hemostasis. It is produced by the liver and is the most abundant coagulation factor in blood plasma. Fibrinogen is a dimeric protein comprising three pairs of polypeptide chains: $\mathrm{A} \alpha, \mathrm{B} \beta$, and $\gamma .{ }^{9}$ Following tissue injury, thrombin cleaves the fibrinopeptide chains to create fibrin monomers, which join together to form insoluble fibrin polymers. ${ }^{11}$ Concurrently, thrombin activates factor XIII, which binds to and cross-links fibrin strands. This stabilizes the clot and increases resistance of the clot to degradation by cross-linking fibrinolytic inhibitors, specifically $\alpha 2$-antiplasmin, into the forming fibrin network. Fibrinogen also binds via glycoprotein IIb/IIIa receptors on the platelet membrane to promote platelet aggregation, thereby localizing platelets to a developing clot.

Table I Main content of cryoprecipitate

\begin{tabular}{|c|c|}
\hline \multicolumn{2}{|c|}{ UK specification (NHSBT) } \\
\hline Fibrinogen & $\begin{array}{l}\text { Specification minimum } 140 \mathrm{mg} / \mathrm{U} \text {. } \\
\text { (Standard adult dose is } 10 \mathrm{U} \text { usually given } \\
\text { as } 2 \times 5 \text { pools) })^{6}\end{array}$ \\
\hline VIII:C & $\begin{array}{l}\text { Mean concentration I0I IU/U } \\
\text { (specification minimum } 70 \text { IU/U) }\end{array}$ \\
\hline \multicolumn{2}{|c|}{ Other content: minimum not specified } \\
\hline Fibronectin & $\begin{array}{l}\text { I,500 mg/mL (normal plasma level } \\
300 \mathrm{mg} / \mathrm{mL} \text { ) }\end{array}$ \\
\hline FXIII & $\begin{array}{l}\sim 20 \%-30 \% \text { original FXIII of plasma } \\
2-3 \text {-fold higher than FFP }\end{array}$ \\
\hline VWF & $\begin{array}{l}\sim 80-100 \mathrm{IU} / \mathrm{U}^{7} \\
(40 \%-70 \% \text { original } \mathrm{VWF} \text { in original plasma) }\end{array}$ \\
\hline Platelet microparticles & 256 times greater than source plasma ${ }^{7}$ \\
\hline
\end{tabular}

Abbreviations: FFP, fresh frozen plasma; NHSBT, National Health Service Blood and Transplant; VWF, von Willebrand factor.

\section{Acquired hypofibrinogenemia}

Fibrinogen levels are particularly susceptible to blood loss and hemodilution, and fibrinogen is the earliest clotting protein to be depleted to critically low levels in major hemorrhage. ${ }^{12}$ Dilution of coagulation factors due to unbalanced resuscitation therapy, consumption, or impaired function of coagulation factors can also contribute to the development of an acquired coagulopathy in major hemorrhage. However, there is evidence that fibrinogen levels fall early even before infusion with intravenous fluids or blood products, eg, in trauma coagulopathy. ${ }^{13}$ A consumptive hypofibrinogenemia may also occur, particularly in the setting of excessive fibrin clot breakdown (hyperfibrinolysis), and the coagulopathy can be compounded by impaired fibrinogen function caused by acidosis, hypothermia, and colloids. ${ }^{14}$ Observational data show that hypofibrinogenemia and hyperfibrinolysis are associated with adverse outcomes in traumatic hemorrhage ${ }^{13}$ and there is increasing recognition of the critical role of fibrinogen in postpartum hemorrhage $\mathrm{e}^{11,15,16}$ and bleeding in cardiac surgery. ${ }^{17-19}$

\section{Use of cryoprecipitate}

Cryoprecipitate is used for two clearly defined clinical indications: hemophilia treatment and supplementation of fibrinogen (both inherited and acquired disease; Table 2).$^{5,10,20}$ But the way cryoprecipitate is used varies worldwide (Table 3). ${ }^{21-23}$ This variation tends to depend on the availability of fibrinogen concentrate as an alternative treatment and whether it is licensed for use in congenital or acquired fibrinogen disorders. Cryoprecipitate is produced in the UK, USA, Canada, Australia, and New Zealand,

Table 2 Sources of fibrinogen replacement

\begin{tabular}{llll}
\hline Product & $\begin{array}{l}\text { Approximate } \\
\text { volume }(\mathrm{mL})\end{array}$ & $\begin{array}{l}\text { Fibrinogen } \\
\text { concentration } \\
(\mathbf{g} / \mathbf{L})\end{array}$ & $\begin{array}{l}\text { Fibrinogen } \\
\text { administered } \\
\text { in one adult } \\
\text { dose }(\mathrm{g})\end{array}$ \\
\hline 4 U FFP & 1,000 & 2 & $2^{\mathrm{a}}$ \\
$\begin{array}{l}\text { Two pools of } 5 \mathrm{U} \\
\text { cryoprecipitate } \\
\text { (= typical adult } \\
\text { dose in UK) }\end{array}$ & 400 & 15 & $3-3.5^{\mathrm{a}}$ \\
$\begin{array}{l}4 \text { g fibrinogen } \\
\text { concentrate }\end{array}$ & $\begin{array}{l}\text { (reconstituted } \\
\text { volume) }\end{array}$ & 20 & \\
\hline
\end{tabular}

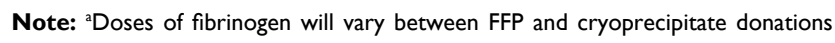
due to differences in donor levels.

Abbreviation: FFP, fresh frozen plasma. 
Table 3 Current indications for cryoprecipitate from NHSBT and British Society for Standards in Haematology Guidelines

DIC with bleeding and a fibrinogen level $<\mathrm{g} / \mathrm{L}$

Acute promyelocytic leukemia - aim fibrinogen $2 \mathrm{~g} / \mathrm{L}$

Advanced liver disease to correct bleeding or as prophylaxis before

surgery when the fibrinogen level is $<\mathrm{g} / \mathrm{L}$

Bleeding associated with thrombolytic therapy causing

hypofibrinogenemia

Hypofibrinogenemia secondary to massive transfusion (keep fibrinogen

$>1.5 \mathrm{~g} / \mathrm{L})$

Renal failure or liver failure associated with abnormal bleeding when desmopressin is contraindicated or ineffective

Inherited hypofibrinogenemia where fibrinogen concentrate is not available

Hypofibrinogenemia in major hemorrhage (pragmatic recommendationaim for level $>1.5 \mathrm{~g} / \mathrm{L}$ )

Abbreviations: NHSBT, National Health Service Blood and Transplant; DIC, disseminated intravascular coagulation.

where it is used for acquired hypofibrinogenemia. But there are few published data outlining the specific uses of cryoprecipitate in low- and middle-income countries. Outside the UK, much of Europe has phased out production of cryoprecipitate, instead favoring fibrinogen concentrate for both congenital and acquired fibrinogen deficiencies. However, fibrinogen concentrate is not universally licensed for acquired hypofibrinogenemia. For example, in countries such as Brazil, Austria, Germany, and the Netherlands, it is licensed for both congenital and acquired fibrinogen deficiency but in the USA, Australia, UK, and Canada it is only licensed for congenital deficiencies. ${ }^{24}$

\section{Inherited bleeding disorders}

After its discovery, cryoprecipitate was first used as a source of FVIII for the treatment of hemophilia. It revolutionized hemophilia treatment and increased life expectancy. ${ }^{4,7}$ It was also found to be of benefit for patients with von Willebrand disease and hypofibrinogenemia. ${ }^{7}$ Since the development of recombinant FVIII with its enhanced safety profile, cryoprecipitate is no longer first-line treatment for hemophilia, and von Willebrand disease, in developed countries, although may still be used in some countries where recombinant products are not readily available. ${ }^{25}$ International guidelines also recommend that fibrinogen concentrate is used first-line for congenital fibrinogen disorders, and cryoprecipitate only if concentrate is not available. ${ }^{26,27}$

\section{Acquired hypofibrinogenemia}

In many countries, cryoprecipitate is administered primarily as a treatment for low fibrinogen levels. Alternative sources of fibrinogen include fibrinogen concentrate and fresh frozen plasma (FFP); cryoprecipitate and fibrinogen concentrate are the only concentrated sources of fibrinogen (Table 2). Given the important emerging roles of fibrinogen and hypofibrinogenemia in obstetric and trauma hemorrhage, there has been much research activity to investigate the threshold and timing of fibrinogen supplementation on patient outcomes. ${ }^{28}$

Indeed, in countries where cryoprecipitate is used, there is considerable variation in practice, despite guidance from national bodies. Three reports of real-world cryoprecipitate usage from Canada, the UK, and Australia highlight practice variations. In Canada, only $24 \%$ of cryoprecipitate transfusions were considered to be transfused appropriately (defined as pretransfusion fibrinogen level $\leq 1 \mathrm{~g} / \mathrm{L}$ in $19 \%$ and posttransfusion fibrinogen level $\leq 1 \mathrm{~g} / \mathrm{L}$ in another $5 \%$ ), $34 \%$ were deemed inappropriate, and in $42 \%$ appropriateness could not be determined. ${ }^{29}$ In a UK survey, 322 cryoprecipitate requests were assessed. ${ }^{30}$ The most common indication was cardiac surgery (32\%) with the majority for active hemorrhage. Trauma and hematology/oncology accounted for $26 \%$ of requests. A pretreatment fibrinogen assay was measured in $74 \%$ episodes in adults. ${ }^{30}$ However, a quarter of cryoprecipitate transfusions were given with no reported indication of hemorrhage, and overall there was variation in the dose of cryoprecipitate transfused. An Australian study showed similar results. ${ }^{31}$ Although the variation in practice and dose may be related to clinical case mix and clinician preference, it also suggests inconsistent practice and uncertainty in the evidence informing optimal use of cryoprecipitate. ${ }^{30}$

In trauma-related major hemorrhage, early empiric transfusion of FFP and red cells is now standard. Data are emerging around the importance of fibrinogen supplementation in this setting. In the UK, a national study prospectively evaluated transfusion practice in trauma hemorrhage, including fibrinogen supplementation at 22 trauma centers (major trauma centers and trauma units) between 2009 and $2011 .{ }^{32}$ The median time to cryoprecipitate transfusion was $156 \mathrm{~min}-$ utes at a major trauma center (184 minutes in a trauma unit), by which time $50 \%$ of patients had died. Although the reasons for delays in cryoprecipitate transfusion were not collected as part of this study, this is an important area where further work is needed to better understand the barriers to timely transfusion support.

\section{Safety}

Cryoprecipitate has been in clinical use for $>50$ years. Overall, there have been very few reports in the literature of adverse events related to cryoprecipitate. ${ }^{3}$ It is not entirely 
clear whether this reflects lack of data collection, reporting bias or in fact a low risk from its use. One of the main safety concerns is the risk of viral transmission with cryoprecipitate, as it does not undergo pasteurization or viral inactivation steps. Efforts to pathogen reduce cryoprecipitate by treatment of plasma with riboflavin and ultraviolet light, amotosalen and UV light, and solvent detergent filtration have met with limited success as these methods generally lead to a $30 \%$ drop in fibrinogen. ${ }^{3}$

The UK hemovigilance scheme, Serious Hazards of Transfusion (SHOT), began to collect and analyze data on adverse events and reactions in blood transfusion in 1996. Between October 1996 and December 2014, no cryoprecipitate-related cases of viral transmission were reported. ${ }^{33}$ Over this same time period, there were five cases of viral transmission with FFP (three Hepatitis E virus [HEV], human immunodeficiency virus [HIV], hepatitis B virus [HBV]). ${ }^{33}$ The 2014 SHOT report recommended avoidance of the use of female donor plasma in the production of cryoprecipitate as there was one case of cryoprecipitate implicated Transfusion Related Acute Lung Injury. However, overall in the 2014 SHOT report, there was a low incidence of acute transfusion reactions attributable to cryoprecipitate (across all blood components $1 / 43$ acute transfusion reactions were due to cryoprecipitate); where cryoprecipitate was issued $>43,150$ times from the UK Blood Services in that year.

\section{Thrombotic complications}

High fibrinogen levels are a known risk factor for thrombosis, in particular arterial thrombosis. Therefore, an important adverse outcome to consider when administering cryoprecipitate or fibrinogen concentrate is the risk of thrombotic events. It is well documented that patients in receipt of large volume transfusion therapy, including cryoprecipitate or other prohemostatic agents (prothrombin complex concentrate and fibrinogen concentrate), for major hemorrhage are at increased risk of thrombosis. ${ }^{34}$ What is not clear is whether there is a direct causal relationship, or indeed how strong the effect might be, between fibrinogen supplementation and thrombotic events in these situations. Data from the CRYOSTAT randomized controlled trial (RCT), which evaluated early cryoprecipitate in trauma hemorrhage, showed no differences in fibrinogen levels at 24 hours and up to 28 days after major hemorrhage therapy, and thrombotic events were only seen in the standard hemorrhage arm, not the early cryoprecipitate arm. ${ }^{35}$

In postsurveillance monitoring, there have been few reported cases of thrombosis with fibrinogen concentrate.
A report into the safety of fibrinogen concentrate, which focused on the treatment of inherited fibrinogen disorders, from 27 years of pharmacovigilance data found 28 reports of possibly related thrombotic events, representing an incidence rate of one event per 23,300 doses (each dose 4 g). ${ }^{27,36}$ Although pharmacovigilance can be limited by underreporting of adverse events, additional safety data are available from several RCTs that used fibrinogen concentrate in surgery.

In a recent multicenter RCT of 500 patients comparing fibrinogen concentrate versus placebo for cardiac surgery (REPLACE trial), no new safety concerns emerged and there was no increase in thromboembolic events for fibrinogen concentrate compared with placebo. ${ }^{37}$ These results and others from previous RCTs of fibrinogen concentrate in surgery summarized by Levy et a $\mathrm{l}^{38}$ do not highlight any thrombotic or safety concerns with fibrinogen concentrate. Further safety and adverse event data should become available for cryoprecipitate and fibrinogen concentrate with increased clinical experience and trials of fibrinogen replacement in active hemorrhage.

\section{The role of cryoprecipitate in resource-restricted countries}

The imbalance between supply and demand of blood products is a global health concern. Data from the World Health Organization show that $\sim 108$ million blood donations are collected every year. ${ }^{39}$ However, nearly half of these blood donations are collected in high-income countries, home to $<20 \%$ of the world's population. In resource-limited countries, the use of virally inactivated factor concentrates may be prohibitive due to cost or availability, and cryoprecipitate is often the only source of clotting factor available. The World Federation of Hemophilia strongly recommends the use of viral-inactivated plasma-derived or recombinant concentrates in preference to cryoprecipitate or FFP for the treatment of hemophilia and other inherited bleeding disorders. ${ }^{40}$ However, where clotting factor concentrates are not available, cryoprecipitate use is justified. ${ }^{40}$ Furthermore, for FXIII deficiency when FXIII concentrate is not available, cryoprecipitate should be considered in preference to FFP due to a higher FXIII content. ${ }^{8,27}$

The development of blood programs strengthening both blood availability and safety is a real need worldwide. ${ }^{41} \mathrm{In}$ countries where cryoprecipitate is the only available option, improving safety becomes paramount, and treatments using solvent/detergent, ${ }^{42-44}$ which do not reduce hemostatic potency, are options that must be considered. 


\section{Evidence for cryoprecipitate use}

Despite its widespread use as a supplement for acquired hypofibrinogenemia in North America and the UK, there are few prospective studies that evaluate the optimal use or effects of cryoprecipitate. The optimal timing and dose of fibrinogen replacement in major bleeding are uncertain. Only one randomized trial, CRYOSTAT, has evaluated early cryoprecipitate in trauma. ${ }^{35}$

\section{Trauma}

It is recognized that fibrinogen is one of the first coagulation factors to be depleted in trauma coagulopathy and early replacement may assist in hemorrhage control. In trauma, FVIII and VWF levels increase, whereas FXIII and fibronectin levels decrease. ${ }^{45}$ Despite this, specific fibrinogen replacement appears late in current major hemorrhage transfusion therapy as seen in observational and prospective studies, eg, PROPPR and PROMMT studies. ${ }^{32,46,47}$ A potential reason for the late administration of cryoprecipitate is the time taken for preparation and thawing (in some centers there is additional time required for pooling of the individual cryoprecipitate units).

A feasibility study from the UK aimed to address whether it was possible to administer two pools of cryoprecipitate within 90 minutes of hospital admission in addition to standard major hemorrhage transfusion in civilian trauma hemorrhage (CRYOSTAT trial). ${ }^{35}$ Cryoprecipitate was chosen, as it is the standard source of fibrinogen in the UK. This study showed that it was feasible to administer cryoprecipitate within 90 minutes (median time $=60$ minutes) and early cryoprecipitate maintained fibrinogen levels $>1.8 \mathrm{~g} / \mathrm{L}$. There was no significant difference in secondary outcomes: thrombotic events, organ failure, length of hospital stay, or mortality although the study was not powered for these outcomes. Blood transfusion requirements in each group were not significantly different. ${ }^{35}$

Fibrinogen replacement in traumatic hemorrhage is an active area of research. Results from forthcoming pilot trials on fibrinogen concentrate in trauma will add to evidence but are not powered to detect differences in mortality. Collectively, these trials will recruit $\sim 300$ patients.

\section{Cardiac surgery and perioperative use}

Cardiac surgery accounts for a significant proportion of cryoprecipitate use. Current guidelines recommend near patient viscoelastic monitoring during cardiopulmonary bypass to guide fibrinogen replacement. ${ }^{48}$ However, there have been very few studies on the efficacy of cryoprecipitate in the perioperative setting.
A head-to-head study of cryoprecipitate versus fibrinogen concentrate in perioperative bleeding in pediatric cardiac surgery was published in $2014 .^{49} \mathrm{In}$ this study of 63 patients, 30 were randomized to receive fibrinogen concentrate and 33 to cryoprecipitate if there was diffuse bleeding present requiring hemostatic therapy and the fibrinogen level was $<1 \mathrm{~g} / \mathrm{L}$. The outcomes of interest were bleeding and transfusion requirements. The results showed that there was no difference in transfusion requirements at 48 hours or in the frequency of adverse effects between the two groups and the authors recommended a larger trial. ${ }^{49}$

In the adult setting, a randomized trial is ongoing, comparing fibrinogen concentrate with cryoprecipitate in patients undergoing cardiopulmonary bypass (TOP-CLOT NCT02540434). Participants will be given cryoprecipitate or fibrinogen concentrate if the ROTEM FIBTEM A10 value is $\leq 10 \mathrm{~mm}$ and microvascular bleeding is present. The primary outcome is number of operative transfusions.

\section{Obstetrics}

There has been no randomized study on cryoprecipitate transfusion in obstetric hemorrhage; trials have evaluated fibrinogen concentrate. A study of patients with postpartum hemorrhage evaluated early fibrinogen concentrate. In this study, 249 patients with active postpartum hemorrhage (PPH) were randomized to either receive $2 \mathrm{~g}$ of fibrinogen concentrate or placebo (saline). ${ }^{50}$ There was no difference in the rate of allogeneic transfusion or mortality between groups. However, patients in the group who received fibrinogen concentrate had fibrinogen levels of $>4 \mathrm{~g}$ at inclusion into the study, and therefore, it is possible that patients with hypofibrinogenemia and bleeding, ie, those at the highest risk of major bleeding, did not receive the therapy, so any benefit could not be observed. ${ }^{50}$

We await the results of a recently completed multicenter randomized trial on early administration of fibrinogen concentrate in obstetric hemorrhage..$^{51}$ In this trial, the main rationale for choosing fibrinogen concentrate as a source of fibrinogen replacement over cryoprecipitate was the inherent delays associated with giving cryoprecipitate (ie, time for thawing and transportation). ${ }^{51}$ Previous work by the same group demonstrated the ability of fibrinogen concentrate to correct fibrinogen rapidly during obstetric hemorrhage..$^{52}$

\section{Cryoprecipitate compared with fibrinogen concentrate}

Fibrinogen concentrate is an alternative source of fibrinogen. Fibrinogen concentrate is produced from a larger pool of 
Table 4 Comparison of cryoprecipitate and fibrinogen concentrate

\begin{tabular}{|c|c|}
\hline Cryoprecipitate & Fibrinogen concentrate \\
\hline No viral inactivation ${ }^{54}$ & Viral inactivation steps (including pasteurization) \\
\hline Dose of fibrinogen varies, less accurate dosing & Known concentration of fibrinogen permits more accurate or targeted dosing \\
\hline $\begin{array}{l}\text { Single unit of cryoprecipitate contains a mean of } \sim 400-460 \mathrm{mg} \text { of } \\
\text { fibrinogen (mean volume } 44 \mathrm{~mL} \text { ) }\end{array}$ & I g fibrinogen concentrate reconstituted in $50 \mathrm{~mL}$ of sterile water \\
\hline $\begin{array}{l}\text { Therapeutic dose for an adult is typically } 2 \times 5 \text { pooled units (total } \\
\text { fibrinogen replacement } 3-3.5 \mathrm{~g} \text { in a volume of } \sim 400 \mathrm{~mL} \text { ) }\end{array}$ & Therapeutic dose dependent on setting of hemorrhage \\
\hline Requires thawing $\sim 15-17$ minutes & $\begin{array}{l}\text { Can be stored at room temperature as lyophilized powder, reconstitution } \\
\text { time } \sim 10 \text { minutes depending on dose (time for reconstitution longer if stored } \\
\text { in the fridge compared with room temperature) }\end{array}$ \\
\hline ABO blood group matching required & No need for $A B O$ blood group matching \\
\hline Contains VIII, VWF, FXIII, and fibronectin in addition to fibrinogen & Contains only fibrinogen \\
\hline In vivo fibrinogen recovery after therapeutic dose $50 \%-62 \%$ & In vivo fibrinogen recovery after therapeutic dose $100 \%-114 \%{ }^{20}$ \\
\hline
\end{tabular}

Abbreviation: VWF, von Willebrand factor.

donors but the overall risk of viral transmission is likely lower compared with cryoprecipitate, as the production involves pasteurization, adsorption, and precipitation, which reduce a significant proportion of enveloped and nonenveloped viruses $^{3,53,54}$ (Table 4).

On the clinical side, there are few comparative data. A systematic review compared cryoprecipitate with fibrinogen concentrate in patients with bleeding. ${ }^{55}$ There was very little available evidence directly comparing fibrinogen concentrate with cryoprecipitate (the review included one RCT and four observational studies). The included studies showed no differences in fibrinogen-level increase, bleeding, red cell transfusions, or thromboembolic complications, and all studies were at risk of bias and the authors concluded that further high-quality trials were needed. ${ }^{55}$

\section{In vivo recovery modeling}

A paper by Collins et $\mathrm{al}^{20}$ described a theoretical tool to model the effect of FFP, cryoprecipitate, and fibrinogen concentrate on a patient's plasma fibrinogen level. In this model, the efficacy of fibrinogen replacement is dependent on the in vivo recovery of each source of fibrinogen. Factors affecting the in vivo recovery including hematocrit, body weight, plasma volume, baseline fibrinogen, target fibrinogen, concentration of fibrinogen in the hemostatic agent, and volume of hemostatic agent were taken into consideration in the development of the model. Although not designed for clinical use, it raises the importance of considering these factors when making decisions regarding the type and dose of fibrinogen replacement. In particular, for cryoprecipitate the precise concentration in each pool is not known and this limits specific dosing. This is an area where there is scope for further research to understand optimal dosing of fibrinogen supplements in different clinical scenarios.

\section{Recent developments in cryoprecipitate} Extended thaw cryoprecipitate

A disadvantage of cryoprecipitate is the potential wastage of units if it is thawed but not used. Guidelines recommend that pooled cryoprecipitate should be used within 4 hours of thawing. ${ }^{6,56,57}$ The main reason for this short lifespan is concerned with suboptimal efficacy and depletion in factor levels once thawed. A recent study evaluated the effect of extended thaw on the level of coagulation proteins in cryoprecipitate. ${ }^{58}$ In this study, 36 individual cryoprecipitate units were thawed, diluted with saline, and assayed over time. ${ }^{58}$ No statistically significant reductions of fibrinogen, FVIII:C, FXIII, and VWF were found after either 4 hours or 24 hours of storage of individual cryoprecipitate units at $20^{\circ} \mathrm{C}-24^{\circ} \mathrm{C} .{ }^{58}$ These data were replicated and extended by a second, more recent study. ${ }^{59}$ Here, testing of $16 \mathrm{U}$ stored at ambient temperature $>72$ hours showed no significant changes in levels of fibrinogen or FXIII. Peak thrombin, endogenous thrombin potential, and all ROTEM variables remained unchanged after 72 hours, showing that the hemostatic properties of thawed pooled cryoprecipitate remained stable. ${ }^{59}$ Although further work is needed to explore the potential risk of bacterial contamination to determine shelf-life before clinical use, the possibility of extended thaw cryoprecipitate may facilitate ready accessibility of thawed cryoprecipitate with reduced wastage.

\section{Other proteins found in cryoprecipitate and their role in hemostasis}

Although cryoprecipitate is used as a source of fibrinogen replacement, it also contains FVIII, VWF, FXIII, fibronectin, and platelet microparticles. 


\section{Fibronectin}

Plasma fibronectin is a dimeric $\alpha 2$-glycoprotein, which is synthesized in the liver and has collagen- and fibrin-binding sites. Depletion of fibronectin has been observed in patients with trauma, burns, sepsis, dissemintated intravascular coagulation (DIC), and after major surgery., ${ }^{7,60}$ In mouse models that investigated the role of fibronectin in hemostasis, mice that lack fibronectin were not able to form stable thrombi at the sites of injured arterioles. ${ }^{61}$ Furthermore, in a fibrinogen knockout model, at the site of vessel injury, plasma fibronectin was rapidly deposited and initiated hemostasis, even before platelet accumulation and integrated into fibrin to increase fibrin fiber diameter and enhance clot strength. ${ }^{62}$ However, whether the fibronectin content in cryoprecipitate transfusion has clinical significance is unproven in clinical studies.

\section{FXIII}

FXIII is a transglutaminase enzyme, which is activated by thrombin. FXIIIa stabilizes the fibrin clot by cross-linking fibrin chains. It also cross-links inhibitors of fibrinolysis, predominantly $\alpha 2$-antiplasmin to fibrin chains, which prevents premature clot lysis and contributes to clot stability. ${ }^{63}$ Patients with trauma-induced coagulopathy have low factor XIII levels ${ }^{45}$ However, although it has been shown that low levels of FXIII are sufficient for mechanical clot stability in healthy patients, there is uncertainty regarding the critical levels of FXIII required in trauma. ${ }^{64} \mathrm{~A}$ flow model showed that FXIII replacement normalized clot lysis in a patient with congenital FXIII deficiency. ${ }^{64}$ Although not tested in the trauma setting or acquired FXIII deficiencies, this interesting observation suggests a possible hemostatic role for FXIII in cryoprecipitate conferring resistance to fibrinolysis.

\section{Platelet microparticles}

Platelet-derived microparticles are the most abundant microparticles in blood and are highly procoagulant with low levels associated with decreased clot strength, greater transfusion requirements, and increased mortality in trauma ${ }^{65}$ Low levels of platelet microparticles were observed in analysis from the PROMMT study on trauma hemorrhage. ${ }^{66}$ However, a recent prospective study in acute trauma did not show any changes in microparticle levels over time.$^{67}$ There is uncertainty regarding their role in trauma and hemostasis and the robustness of quantitative and qualitative assays may need addressing before their role in trauma coagulopathy can be elucidated. ${ }^{68}$

\section{Cryoprecipitate: use and future directions}

Globally, there is $>50$ years of clinical experience of cryoprecipitate. The main indication for cryoprecipitate transfusion today is for replacement of low fibrinogen in hemorrhage. Although there have been very few reports of viral transmission or other adverse complications with cryoprecipitate (possibly due to lack of reporting), many countries have moved to fibrinogen concentrate. Advantages of fibrinogen concentrate compared with cryoprecipitate include additional safety measures for reducing viral transmission, near-patient availability, and transportability (particularly relevant in the field). However, with recent preclinical studies showing stability of fibrinogen levels in thawed cryoprecipitate, this has the potential to make cryoprecipitate more rapidly available for transfusion, and future studies may evaluate the efficacy of prethawed cryoprecipitate.

The discrepancy among licenses for fibrinogen concentrate in acquired hypofibrinogenemia and differences in cryoprecipitate use show that there are gaps in knowledge that need to be addressed by high-quality trials including assessment of cost-effectiveness and optimal dose of fibrinogen. ${ }^{19,24,68}$ So far, there have not been any head-to-head efficacy trials of cryoprecipitate versus fibrinogen concentrate in bleeding, but only pilot studies in cardiac surgery and trauma.

It is becoming clearer that the patterns and mechanisms of coagulopathy in major bleeding may differ according to the type of bleed. Whether the additional proteins, VIII, VWF, fibronectin, and XIII, found in cryoprecipitate have a beneficial effect on hemostasis remains unclear. As we begin to understand more about the complexities of hemostatic pathways and the patterns of bleeding and coagulopathy seen in different types of hemorrhage, it is becoming clearer that optimal blood product support in major hemorrhage may need to venture beyond generic major hemorrhage protocols to a more individualized approach. We await further prospective evidence to guide the optimal source, timing, and dose of fibrinogen replacement in hemorrhage. We anticipate a significant growth in our clinical understanding over the next few years as a number of prospective studies on fibrinogen concentrate in bleeding are reported. Further work is needed to evaluate whether the additional proteins in cryoprecipitate confer any hemostatic benefit over fibrinogen concentrate in different types of bleeding.

\section{Disclosure}

NC was principal investigator of the CRYOSTAT trial, a feasibility trial evaluating early cryoprecipitate transfusion in trauma hemorrhage. $\mathrm{NC}$ is on the advisory board for LFB 
and has received an investigator-led research grant from CSL Behring. HW is involved in an investigator-led study funded by CSL Behring. The authors report no other conflicts of interest in this work.

\section{References}

1. Pool JG, Gershgold EJ, Pappenhagen AR. High-potency antihaemophilic factor concentrate prepared from cryoglobulin precipitate. Nature. 1964;203:312.

2. Kasper CK. Judith Pool and the discovery of cryoprecipitate. Haemophilia. 2012;18(6):833-835.

3. Nascimento B, Goodnough LT, Levy JH. Cryoprecipitate therapy. Br J Anaesth. 2014;113(6):922-934.

4. Sørensen B, Bevan D. A critical evaluation of cryoprecipitate for replacement of fibrinogen. Br J Haematol. 2010;149(6):834-843.

5. Yang L, Stanworth S, Baglin T. Cryoprecipitate: an outmoded treatment? Transfus Med. 2012;22(5):315-320.

6. Guidelines for the Blood Transfusion Services in the United Kingdom [webpage on the Internet]. Chapter 7: Specifications for Blood Components. 8th ed.suppl 2013. Available from: http://www.transfusionguidelines.org/red-book/chapter-7-specifications-for-bloodcomponents/7-18-cryoprecipitate-pooled-leucocyte-depleted. Accessed May 27, 2016.

7. Callum JL, Karkouti K, Lin Y. Cryoprecipitate: the current state of knowledge. Transfus Med Rev. 2009;23(3):177-188.

8. Caudill JS, Nichols WL, Plumhoff EA, et al. Comparison of coagulation factor XIII content and concentration in cryoprecipitate and fresh-frozen plasma. Transfusion. 2009;49(4):765-770.

9. Sachais BS, Shaz BH. Early cryoprecipitate for trauma patients is feasible, but will it improve outcome? Br J Anaesth. 2015;115(1):3-5.

10. NHSBT [webpage on the Internet]. NHSBT Portfolio of Blood Components and Guidance for their Clinical Use. 2014. Available from: http:// hospital.blood.co.uk/media/27048/spn223-v6-2.pdf. Accessed May 27, 2016.

11. Levy JH, Goodnough LT. How I use fibrinogen replacement therapy in acquired bleeding. Blood. 2015;125(9):1387-1393.

12. Hiippala ST, Myllylä GJ, Vahtera EM. Hemostatic factors and replacement of major blood loss with plasma-poor red cell concentrates. Anesth Analg. 1995;81(2):360-365.

13. Rourke C, Curry N, Khan S, et al. Fibrinogen levels during trauma hemorrhage, response to replacement therapy, and association with patient outcomes. J Thromb Haemost. 2012;10(7):1342-1351.

14. Lunde J, Stensballe J, Wikkelsø A, Johansen M, Afshari A. Fibrinogen concentrate for bleeding-a systematic review. Acta Anaesthesiol Scand. 2014;58(9):1061-1074.

15. Collis RE, Collins PW. Haemostatic management of obstetric hemorrhage. Anaesthesia. 2015;70(suppl 1):78-86.

16. Green L, Knight M, Seeney F, et al. The haematological features and transfusion management of women who required massive transfusion for major obstetric hemorrhage in the UK: a population based study. Br J Haematol. 2016;172(2):616-624.

17. Kindo M, Minh TM, Gerelli S, et al. Plasma fibrinogen level on admission to the intensive care unit is a powerful predictor of postoperative bleeding after cardiac surgery with cardiopulmonary bypass. Thromb Res. 2014;134(2):360-368.

18. Pillai R, Fraser JF, Ziegenfuss M, Bhaskar B. Influence of circulating levels of fibrinogen and perioperative coagulation parameters on predicting postoperative blood loss in cardiac surgery: a prospective observational study. J Card Surg. 2014;29(2):189-195.

19. Ranucci M, Pistuddi V, Baryshnikova E, Colella D, Bianchi P. Fibrinogen levels after cardiac surgical procedures: association with postoperative bleeding, trigger values, and target values. Ann Thorac Surg. 2016;102(1):78-85.

20. Collins PW, Solomon C, Sutor K, et al. Theoretical modeling of fibrinogen supplementation with therapeutic plasma, cryoprecipitate, or fibrinogen concentrate. Br J Anaesth. 2014;113(4):585-595.
21. O'Shaughnessy DF, Atterbury C, Bolton Maggs P, et al. Guidelines for the use of fresh-frozen plasma, cryoprecipitate and cryosupernatant. $\mathrm{Br}$ J Haematol. 2004;126(1):11-28.

22. Transfusion Task Force. Amendments and corrections to the "Transfusion Guidelines for neonates and older children" (BCSH, 2004a); and to the "Guidelines for the use of fresh frozen plasma, cryoprecipitate and cryosupernatant” (BCSH, 2004b). Br J Haematol. 2007;136(3):514-516.

23. Hunt BJ, Allard S, Keeling D, Norfolk D, Stanworth SJ, Pendry K. A practical guideline for the haematological management of major haemorrhage. Br J Haematol. 2015;170(6):788-803.

24. Costa-Filho R, Hochleitner G, Wendt M, Teruya A, Spahn DR. Over 50 years of fibrinogen concentrate. Clin Appl Thromb Hemost. 2016;22(2): $109-114$.

25. Pereira A. Cryoprecipitate versus commercial fibrinogen concentrate in patients who occasionally require a therapeutic supply of fibrinogen: risk comparison in the case of an emerging transfusion-transmitted infection. Haematologica. 2007;92(6):846-849.

26. Mumford AD, Ackroyd S, Alikhan R, et al. Guideline for the diagnosis and management of the rare coagulation disorders: a United Kingdom Haemophilia Centre Doctors' Organization guideline on behalf of the British Committee for Standards in Haematology. Br J Haematol. 2014;167(3):304-326.

27. Palla R, Peyvandi F, Shapiro AD. Rare bleeding disorders: diagnosis and treatment. Blood. 2015;125(13):2052-2061.

28. Bolliner D, Tanaka KA. Haemostatic efficacy of fibrinogen concentrate: is it the threshold or timing of therapy? Br J Anaesth. 2015;115(2): $158-161$.

29. Alport EC, Callum JL, Nahirniak S, Eurich B, Hume HA. Cryoprecipitate use in 25 Canadian hospitals: commonly used outside of the published guidelines. Transfusion. 2008;48(10):2122-2127.

30. Tinegate H, Allard S, Grant-Casey J, et al. Cryoprecipitate for transfusion: which patients receive it and why? A study of patterns of use across three regions in England. Transfus Med. 2012;22(5):356-361.

31. Anderson MA, Glazebrook B, Cutts B, Stevenson L, Bielby L, Borosak M. When do we transfuse cryoprecipitate? Intern Med J.2013;43(8):896-902.

32. Stanworth SJ, Davenport R, Curry N, et al. Continuing high mortality from trauma haemorrhage and opportunities for improvement in transfusion practice: an observational study in England and Wales. Br J Surg. 2016;103(4):357-365.

33. Bolton-Maggs PHB, Poles D et al On Behalf of the Serious Hazards of Transfusion (SHOT) Steering Group. The 2014 Annual SHOT Report. Manchester, UK. 2015.

34. Ozier Y, Hunt BJ. Fibrinogen concentrate for management of bleeding: against indiscriminate use. J Thromb Haemost. 2011;9:6-8.

35. Curry N, Rourke C, Davenport R, Beer S, Pankhurst L, Deary A. Early cryoprecipitate for major haemorrhage in trauma: a randomised controlled feasibility trial. Br J Anaesth. 2015;115:76-83.

36. Solomon C, Gröner A, Ye J, Pendrak I. Safety of fibrinogen concentrate: analysis of more than 27 years of pharmacovigilance data. Thromb Haemost. 2015;113(4):759-771.

37. Rahe-Meyer N, Levy JH, Mazer CD, et al. Randomized evaluation of fibrinogen vs placebo in complex cardiovascular surgery (REPLACE): a double-blind phase III study of haemostatic therapy. Br JAnaesth. 2016; 117(1):41-51.

38. Levy JH, Welsby I, Goodnough LT. Fibrinogen as a therapeutic target for bleeding: a review of critical levels and replacement therapy. Transfusion. 2014;54(5):1389-1405.

39. WHO [webpage on the Internet]. Available from: http://www.who.int/ mediacentre/news/releases/2016/world-blood-donor-day/en/. Accessed May 14, 2016.

40. Srivastava A, Brewer AK, Mauser-Bunschoten EP, et al. Guidelines for the management of hemophilia. Haemophilia. 2013;19(1):e1-e47.

41. McCullough TK, McCullough J. Strengthening blood programs in developing countries. Transfus Apher Sci. 2013;49(3):408-415.

42. Burnouf T, Goubran HA, Radosevich M, Sayed MA, Gorgy G, ElEkiaby M. A minipool process for solvent-detergent treatment of cryoprecipitate at blood centres using a disposable bag system. Vox Sang. 2006;91(1):56-62. 
43. El-Ekiaby M, Sayed MA, Caron C, et al. Solvent-detergent filtered (S/D-F) fresh frozen plasma and cryoprecipitate minipools prepared in a newly designed integral disposable processing bag system. Transfus Med. 2010;20(1):48-61.

44. El-Ekiaby M, Goubran HA, Radosevich M, Abd-Allah A, El-Ekiaby A, Burnouf T. Pharmacokinetic study of minipooled solvent/detergentfiltered cryoprecipitate factor VIII. Haemophilia. 2011;17(5): e884-e888.

45. Johansson PI, Sørensen AM, Perner A, et al. Disseminated intravascular coagulation or acute coagulopathy of trauma shock early after trauma? An observational study. Crit Care. 2011;15(6):R272.

46. Holcomb JB, Tilley BC, Baraniuk S, et al. Transfusion of plasma, platelets, and red blood cells in a 1:1:1 vs a 1:1:2 ratio and mortality in patients with severe trauma: the PROPPR randomized clinical trial. JAMA. 2015; 313(5):471-482.

47. Holcomb JB, del Junco DJ, Fox EE, et al; PROMMTT Study Group. The prospective, observational, multicenter, major trauma transfusion (PROMMTT) study: comparative effectiveness of a time-varying treatment with competing risks. JAMA Surg. 2013;148(2):127-136.

48. Kozek-Langenecker SA, Afshari A, Albaladejo P, et al. Management of severe perioperative bleeding. Guidelines from the European Society of Anaesthesiology. Eur J Anaesthesiol. 2013;30(6): 270-382.

49. Galas FR, de Almeida JP, Fukushima JT, et al. Hemostatic effects of fibrinogen concentrate compared with cryoprecipitate in children after cardiac surgery: a randomized pilot trial. J Thorac Cardiovasc Surg. 2014;148(4):1647-1655.

50. Wikkelsø AJ, Edwards HM, Afshari A, et al. Pre-emptive treatment with fibrinogen concentrate for postpartum haemorrhage: randomized controlled trial. Br J Anaesth. 2015;14(4):623-633.

51. Aawar N, Alikhan R, Bruynseels D, et al. Fibrinogen concentrate versus placebo for treatment of postpartum haemorrhage: study protocol for a randomised controlled trial. Trials. 2015;16:169.

52. Bell SF, Rayment R, Collins PW, Collis RE. The use of fibrinogen concentrate to correct hypofibrinogenaemia rapidly during obstetric haemorrhage. Int J Obstet Anesth. 2010;19(2):218-223.

53. NHSBT [webpage on the Internet]. NHSBT Factsheet Standard Cryoprecipitate and Methylene Blue treated Cryoprecipitate. 2016. Available from: http://hospital.blood.co.uk/media/27096/140904-standardcryoprecipitate-a5-factsheet.pdf. Accessed May 26, 2016.

54. Franchini M, Lippi G. Fibrinogen replacement therapy: a critical review of the literature. Blood Transfus. 2012;10(1):23-27.
55. Jensen NH, Stensballe J, Afshari A. Comparing efficacy and safety of fibrinogen concentrate to cryoprecipitate in bleeding patients: a systematic review. Acta Anaesthesiol Scand. 2016;60(8):1033-1042.

56. $\mathrm{AABB} / \mathrm{ABC} / \mathrm{ARC} / \mathrm{ASBP}$ [webpage on the Internet]. Circular of Information for the Use of Human Blood and Blood Components. 2013. Available from: http://www.aabb.org/tm/coi/Documents/coi1113.pdf. Accessed May 27, 2016.

57. Canadian Blood Services [webpage on the Internet]. Circular of Information. 2016. Available from: https:/www.blood.ca/sites/default/files/ COI_CPDPlasmaFFPA.pdf. Accessed May 27, 2016.

58. Sheffield WP, Bhakta V, Jenkins C. Stability of coagulation protein activities in single units or pools of cryoprecipitate during storage at $20-24^{\circ} \mathrm{C}$ for up to 24 h. Vox Sang. 2016;110(1):12-19.

59. Green L, Backholer L, Wiltshire M, Platton S, Stanworth SJ, Cardigan $\mathrm{R}$. The hemostatic properties of thawed pooled cryoprecipitate up to 72 hours. Transfusion. 2016;56(6):1356-1361.

60. Reilly JT, McVerry BA, Mackie MJ. Fibronectin in blood products-an in vitro and in vivo study. J Clin Pathol. 1983;36:1377-1381.

61. Hou Y, Carrim N, Wang Y, Gallant RC, Marshall A, Ni H. Platelets in hemostasis and thrombosis: novel mechanisms of fibrinogen-independent platelet aggregation and fibronectin-mediated protein wave of hemostasis. J Biomed Res. 2015;29:437-444.

62. Wang Y, Reheman A, Spring CM. Plasma fibronectin supports hemostasis and regulates thrombosis. J Clin Invest. 2014;124(10):4281-4293.

63. Mutch NJ, Koikkalainen JS, Fraser SR, et al. Model thrombi formed under flow reveal the role of factor XIII-mediated cross-linking in resistance to fibrinolysis. J Thromb Haemost. 2010;8(9):2017-2024.

64. Schroeder V, Kohler HP. New developments in the area of factor XIII J Thromb Haemost. 2013;11(2):234-244.

65. Curry N, Raja A, Beavis J, Stanworth S, Harrison P. Levels of procoagulant microvesicles are elevated after traumatic injury and platelet microvesicles are negatively correlated with mortality. $J$ Extracell Vesicles. 2014;3:25625

66. Windeløv NA, Sørensen AM, Perner A, et al. Platelet aggregation following trauma: a prospective study. Blood Coagul Fibrinolysis. 2014;25(1): 67-73.

67. Park MS, Xue A, Spears GM, et al. Thrombin generation and procoagulant microparticle profiles after acute trauma: a prospective cohort study. J Trauma Acute Care Surg. 2015;79(5):726-731.

68. Stanworth SJ, Hunt BJ. The desperate need for good-quality clinical trials to evaluate the optimal source and dose of fibrinogen in managing bleeding. Crit Care. 2011;15(6):1006.
International Journal of Clinical Transfusion Medicine

\section{Publish your work in this journal}

International Journal of Clinical Transfusion Medicine is an international, peer-reviewed, open access, online journal publishing clinicalexperimental, policy-making and evidence-based practices of all topics pertaining to clinical transfusion medicine. Original research, short reports, reviews, case reports and commentaries are invited
Dovepress

The manuscript management system is completely online and includes a very quick and fair peer-review system, which is all easy to use. Visit http://www.dovepress.com/testimonials.php to read real quotes from published authors. 